\title{
Socio-Economic Determinants of HIV-Malaria Co-Infection among Adults in the North Central Zone, Nigeria
}

\author{
Omotayo S. Alaofin ${ }^{1}$, Kantharuben Naidoo ${ }^{2} \&$ Wilbert Sibanda $^{3}$ \\ ${ }^{1}$ Discipline of Public Health Medicine, School of Nursing and Public Health, University of KwaZulu-Natal, \\ Durban, South Africa \\ ${ }^{2}$ Discipline of Family Medicine, School of Nursing and Public Health, University of KwaZulu-Natal, Durban, \\ South Africa \\ ${ }^{3}$ School of Mathematics, Statistics and computer science, University of KwaZulu-Natal, Durban, South Africa \\ Correspondence: Omotayo S. Alaofin, Department of public health medicine, University of KwaZulu-Natal, \\ Durban 4001, South Africa. Tel: 27-78-052-8980. Fax: 27-031-260-4465. E-mail: alaofinomotayo@gmail.com
}

Received: June 24, 2019 Accepted: July 8, 2019 Online Published: November 30, 2019

doi:10.5539/gjhs.v12n1p9 URL: https://doi.org/10.5539/gjhs.v12n1p9

\begin{abstract}
Background: Globally, Human Immunodeficiency Virus, and malaria co-infection are responsible for high rates of disease and death predominantly in sub-Saharan Africa. However, the relationship between the socio-economic determinants of the human immunodeficiency virus and malaria co-infection has not been established. Therefore, this study aims to determine the socio-economic variables associated with human immunodeficiency virus and malaria co-infection among adults in peri-urban secondary hospitals in the North Central Zone, Nigeria.
\end{abstract}

Method: A retrospective descriptive cross-sectional study was carried out among human immunodeficiency virus-positive patients at six selected peri-urban secondary hospital facilities in the North Central Zone, Nigeria. Continuos variable was compared using the student t-test, or Wilcoxon test, while the categorical variable was compared using Chi-square and Fisher's exact test. The significance level was kept at $\mathrm{p} \leq 0.05$.

Results: This study showed that patients of 61 years and above, those between 18 and 30 years of age are at risk of HIV/malaria co-infection RR $1.09(0.92-1.31)$ and $(95 \% \mathrm{CI}), 1.02(0.96-1.08)$. A significant relationship was reported between the likelihood of co-infection and education $(p=0.023)$, residence $(p=0.001)$, employment, $(p<$ $0.001)$ and income $(p<0.001)$. Similarly, the highest proportion of malaria diagnosis $547(80.9 \%)$ was among the un-employed patient's contrary to the least proportion reported among employed patients $84(68.3 \%)$. Using a logistic regression model, it was noted that the proportion of co-infection among HIV seropositive patients is negatively associated with their income.

Conclusion: Findings from this study revealed a strong association between socio-economic variables and HIV/malaria co-infection among the study population. These socio-economic variables could serve as an essential indicator in any proposed intervention programme and could help to predict future co-infection rates in regions where both infectious diseases are dominant.

Keywords: "adults", "co-infection", "HIV/AIDS", "malaria", "Nigeria", "socio-economic variables

\section{Introduction}

The health outcome and the quality of life of an individual largely depend on the socio-economic factors (Heiman \& Artiga, 2015). An important health indicator on which other health determinants such as employment status, education, educational level, income, and the living environment largely depends on, is the socio-economic status (SES) (Parcel \& Mueller, 1983). Malaria and Human Immunodeficiency Virus/Acquired Immunodeficiency Syndrome (HIV/AIDS) are the two major causes of morbidity and mortality worldwide (Berg et al., 2014). More than two million annual deaths globally were attributed to the public health impact of HIV and malaria (Mukandavire, Gumel, Garira, \& Tchuenche, 2009); (WHO, 2016), majority of which are in sub-Saharan Africa (SSA). Furthermore, higher co-infection rates are responsible for more than 300,000 HIV/AIDS-related deaths in 2013, coupled with a 12 billion dollar loss associated with decreased productivity (World Health Organization, 2005). Nigeria, being the second largest country with HIV seropositive individuals globally by population, position top among African countries tormented by HIV/AIDS with the most significant malaria infection in 
sub-Saharan Africa (WHO, 2008). High levels of co-infection occur largely in sub-Saharan Africa where the immune deficiency caused by the HIV supports malaria co-infection and transmission which impacts malaria control efforts (Whitworth et al., 2000). Furthermore, malaria increases HIV replication, disease progression and spread (Ogunmola, Oladosu, \& Olamoyegun, 2014), (Akinbo et al., 2016). There is limited information on the relationship between the socio-economic variable and HIV/malaria co-infection at peri-urban secondary hospital (Ogunmola et al., 2014). Therefore, this study aims to ascertain the socio-economic determinants of HIV/malaria co-infection in North Central Zone (NCZ) Nigeria.

\section{Methodology}

\subsection{Research Settings}

The research study was conducted in three out of the six states in the NCZ of Nigeria. The three states were selected based on the state by state HIV prevalence. Two states where the HIV prevalence is higher than the national HIV seroprevalence rate and one state with lower prevalence rate. The research study was conducted in Nasarawa, Benue and Kwara State, all in the NCZ, between March 1, 2018, and October 31, 2018. The selected states were further divided into senatorial districts, and two senatorial districts were randomly selected from each state. One semi-urban public secondary health care facility was purposively selected from each senatorial district for the research study. The hospital facilities selected for the study are comprehensive HIV/AIDS treatment centers where HIV/AIDS management clinics and services are provided.

\subsection{Participants}

The target population in this research study are medically diagnosed adult HIV positive patients, 18 years and above, registered and receiving treatment at the selected semi-urban secondary hospital facilities. Case files of adult HIV positive patients who had not missed their scheduled visits for three consecutive times were selected for the study and reviewed retrospectively. Case files of HIV positive patients that were less than 18 years and HIV positive patients who had missed clinic appointment for more than three times were excluded from the study. The total number of case files that met the inclusion criteria is 1,472 out of the 1,652 case files that were randomly reviewed for the research study across the six selected hospital facilities.

\subsection{Data Collection}

Two trained volunteer workers were recruited as research assistants for data collection at all the research clinics namely; Specialist hospital Omu-Aran, specialist hospital Offa, Gboko general hospital, Katsina-Ala general hospital. Others include Nasarawa Eggon general hospital and Obi general hospital all in the NCZ Nigeria. The case files review tool adapted from (Adu-Gyasi et al., 2013), was used as data collection instrument. Case files of the patient were randomly selected from the patient registered at all the participating clinics. Data collected at each patient files include; the date and age at which the patient registered at the clinic, gender, socio-demographic and socio-economic profile. For each patient, data were collected retrospectively over five years between January 1st, 2013 to December 31st, 2017.

\subsection{Data Analysis}

Data generated from case files was reprocessed to determine error and omissions before entering the data into Statistical Package for Social Sciences (SPSS) version 25. Continuous variable such as patient age was summarised as mean $\pm \mathrm{SD}$ or median, interquartile range and compared using students t-test or Wilcoxon test as appropriate. Categorical variable such as gender were expressed as proportion and compared using Chi-square and Fisher's exact test was used to ascertain the possibility of co-infection between the socio-economic variable and HIV and malaria. Odds ratios with $95 \%$ confidence interval $(95 \% \mathrm{CI})$ were estimated to measure the strengths of the associations. The level of significance was kept at $\mathrm{p} \leq 0.05$.

\subsection{Ethical Consideration}

The protocol for the research study was reviewed and approved by the University of KwaZulu-Natal Biomedical Research Ethics Committee (BREC)- Reference Number: BE654/17. The research protocol was also submitted to and approved by the Kwara State Ministry of Health (MOH/KS/EU/777/225), the Benue State Ministry of Health (MOH/STA/204/56), and the Nasarawa State Ministry of Health (Registration Number: NHREC 18/06/2017). Ethical approval issued by the ethics committee at all the state ministry of health covers the waiver of informed consent for participant information reviewed from the patient case files. Gatekeepers' letter/administrative clearance was also granted at all six study locations. 


\section{Results}

Table 1. Socio-demographic variables associated with socio-economic determinants of HIV/malaria co-infection in the north central zone Nigeria

\begin{tabular}{|c|c|c|c|}
\hline $\begin{array}{l}\text { Socio-demographic } \\
\text { variables }\end{array}$ & $\begin{array}{l}\text { Frequency n }(\%) \\
(\mathrm{N}=\mathbf{1 , 4 7 2 )}\end{array}$ & $\begin{array}{l}\text { Co-infected Patients n (\%) } \\
(N=1,101)\end{array}$ & $\begin{array}{l}\text { Relative risk } \\
\text { RR (95\% CI) }\end{array}$ \\
\hline \multicolumn{4}{|l|}{ Gender } \\
\hline Male & $421(100.0)$ & $325(77.1)$ & $1.82(1.69-1.96)$ \\
\hline Female & $1,051(100.0)$ & $776(73.8)$ & $0.96(0.90-1.02)$ \\
\hline Total & 1472 & 1,101 & \\
\hline \multicolumn{4}{|l|}{ Age group } \\
\hline $18-<30$ & $635(43.13)$ & $480(75.5)$ & $1.02(0.96-1.08)$ \\
\hline $31-40$ & 485 (32.95) & $360(74.2)$ & $0.99(0.93-1.05)$ \\
\hline $41-50$ & $236(16.04)$ & $176(74.5)$ & $0.997(0.92-1.08)$ \\
\hline $51-60$ & $89(6.05)$ & $63(70.7)$ & $0.94(0.82-1.08)$ \\
\hline$\geq 61$ & $27(1.83)$ & $22(81.4)$ & $1.09(0.92-1.31)$ \\
\hline Total & 1472 & 1,101 & \\
\hline \multicolumn{4}{|l|}{ Marital status } \\
\hline Single & $173(11.75)$ & $142(82.0)$ & $1.1(0.89-1.35)$ \\
\hline Married & $1,100(74.72)$ & $806(73.2)$ & $0.98(0.94-1.03)$ \\
\hline Divorced & $11(0,75)$ & $9(81.8)$ & $1.09(0.45-2.6)$ \\
\hline Separated & $59(4.01)$ & $45(76.2)$ & $1.02(0.70-1.49)$ \\
\hline Cohabiting & $2(0.14)$ & $1(50.0)$ & $0.67(0.06-7.36)$ \\
\hline Widowed & $127(8.63)$ & $98(79.0)$ & $1.03(0.80-1.32)$ \\
\hline Total & 1472 & 1,101 & \\
\hline \multicolumn{4}{|l|}{ Ethnicity } \\
\hline Yoruba & $128(8.69)$ & $71(55.4)$ & $0.74(056-0.98)$ \\
\hline Igbo & $23(1.57)$ & $20(86.9)$ & $1.16(0.64-2.1)$ \\
\hline Hausa & $478(32.47)$ & $343(71.7)$ & $0.81(0.72-0.91)$ \\
\hline Others & 843 (57.27) & $667(79.1)$ & $0.90(0.84-0.96)$ \\
\hline Total & 1472 & 1,101 & \\
\hline \multicolumn{4}{|l|}{ Religion } \\
\hline Christianity & $940(63.86)$ & $735(78.1)$ & $1.05(0.99-1.11)$ \\
\hline Islam & $528(35.87)$ & $363(68.7)$ & $0.92(0.882-1.02)$ \\
\hline Traditional religion & $4(0.27)$ & $3(75.0)$ & $1.00(0-22-4.47)$ \\
\hline Total & 1472 & 1,101 & \\
\hline
\end{tabular}

A total number of 1,652 case files of patient were included in this study, out of which 1,472 met the inclusion criteria. Out of the entire group of co-infected patients, females have the highest proportion $776(73.8 \%)$. However, investigating the rate of co-infection with each gender, males presented with the highest proportion. Therefore, the relative risk was higher in males (RR $1.82,95 \%$ CI $1.69-1.96$ ), with a significant relationship $p$-value $\leq 0.05$, than in females (RR 0.96, 95\% CI 0.90 - 1.02) (Table 1). Age group above 61 years demonstrated the highest risk of co-infection (RR 1.09, 95\% CI 0.92 - 1.31), even though the relative risk was not statistically significant. Risk of co-infection was lowest among the age group 31 to $40 \mathrm{RR} 0.99,95 \% \mathrm{CI} 0.93-1.05$ ). Patient ages ranged between 
18 and 73 years old with an average age of $35.0 \pm 10.3$ years and median age of $32(\mathrm{IQR}=13)$ years. The average duration on ART for each patient was $1.6(\mathrm{SD})=0.5$ years with a median duration of 2 (interquartile range 1-2 years), and using the Shapiro-Wilks test for normality, ART duration was non-normally distributed, $p$-value $=$ 0.000 .

Table 2. Association between the socio-economic determinants of HIV/malaria co-infection among adults in the north central zone, Nigeria

\begin{tabular}{|c|c|c|c|}
\hline Variable & Frequency $n(\%)(n=1,472)$ & Co-infected Patients n $(\%)(\mathrm{N}=1,101)$ & P-value \\
\hline \multicolumn{4}{|l|}{ Educational status } \\
\hline No formal education & $549(37.29)$ & $421(76.6)$ & \\
\hline Completed primary & $382(25.95)$ & $272(71.2)$ & \\
\hline Completed secondary & $361(24.53)$ & $282(78.1)$ & \\
\hline Completed tertiary & $180(12.23)$ & $126(70.0)$ & \\
\hline Total & 1,472 & 1,101 & 0.023 \\
\hline \multicolumn{4}{|l|}{ Residence } \\
\hline Urban & $122(8.28)$ & $100(81.9)$ & \\
\hline Rural & $1,025(69.64)$ & $772(75.3)$ & \\
\hline Peri-urban & $325(22.08)$ & $229(70.4)$ & \\
\hline Total & 1,472 & 1,101 & 0.001 \\
\hline \multicolumn{4}{|l|}{ Distance from hospital } \\
\hline Less than 15 minutes & $39(2.65)$ & $28(71.7)$ & \\
\hline$>15$ to 30 minutes & $294(19.97)$ & $219(74.4)$ & \\
\hline$>30$ to 45 minutes & $509(34.58)$ & $389(76.5)$ & \\
\hline$>45$ to $1 \mathrm{~h}$ & $500(33.97)$ & $367(73.4)$ & \\
\hline More than 1 hour & $130(8.83)$ & $98(75.3)$ & \\
\hline Total & 1,472 & 1101 & $0.75 *$ \\
\hline \multicolumn{4}{|l|}{ Employment } \\
\hline Employed & $123(8.35)$ & $85(69.1)$ & \\
\hline Un-employed & $668(45.39)$ & $547(81.8)$ & \\
\hline Self employed & $681(46.26)$ & $469(68.8)$ & \\
\hline Total & 1,472 & 1,101 & 0.000 \\
\hline \multicolumn{4}{|l|}{ Income } \\
\hline Less than 30,000 & $585(72.76)$ & $403(68.8)$ & \\
\hline$>30,000-80,000$ & $161(20.03)$ & $125(77.6)$ & \\
\hline$>80,000-130,000$ & $40(4.97)$ & $21(52.5)$ & \\
\hline$>130,000-180,000$ & $18(2.24)$ & $1(5.5)$ & \\
\hline Total & 804 & 550 & 0.000 \\
\hline
\end{tabular}

$1 \mathrm{USD}=363.67 \mathrm{NGN}$ in 2018 .

$\mathrm{HIV} /$ malaria co-infection is more dominant among HIV positive patients with secondary education $78 \%$ and least frequently in participants with tertiary education $70 \%$. Considering all the type of residence, the highest proportion of co-infected patients were found to be among urban residence (Table 2). Using a chi-square test, a significant association was observed between the likelihood of HIV/malaria co-infection and education, residence, employment and income. However, patients who were employed and those that live closer to the hospital facility 
were least co-infected. It was also observed that individuals with the highest monthly income were least co-infected with HIV and malaria (5.5\%). However, only the distance from the hospital facility indicated no significant association between HIV/malaria co-infection ( $p$-value 0.75$)$ among the patients.

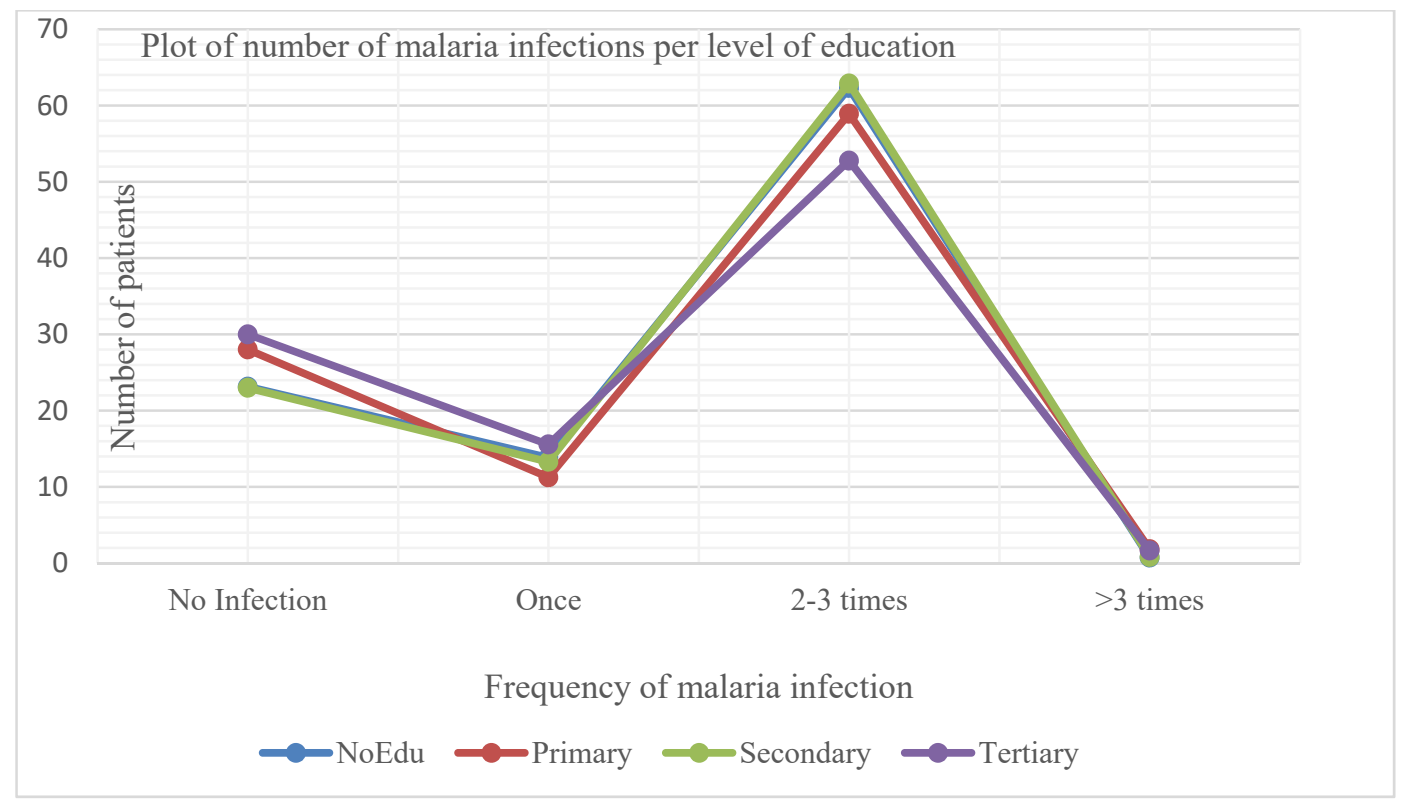

Figure 1. Relationship between the educational status and number of malaria infection

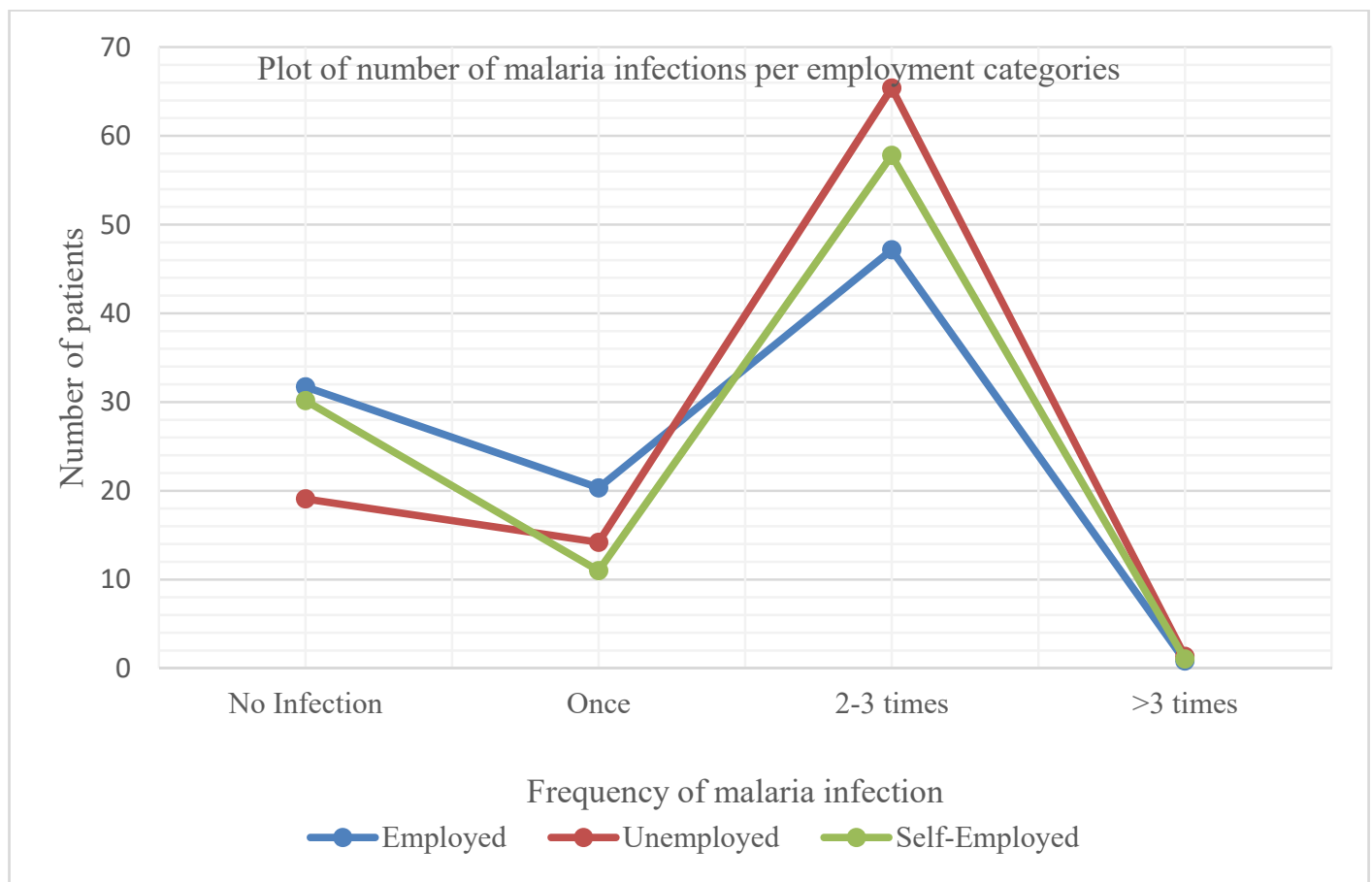

Figure 2. Relationship between the number of malaria infection and patients' employment categories

Patients with minimal formal education has the highest proportion of malaria between two and three times in the last five years, while the lowest proportion was documented among those with tertiary education. As the proportion of all patient, patient with no formal education comprises $34 \%, 39 \%, 38 \%$, and $24 \%$ of patient with no malaria infection, single infection, 2 to 3 times infection, and more than three infections respectively. It was observed that the majority of the patients $60 \%$ have two to three times of malaria infection. Therefore, people with 
no formal education make up only $39 \%$ of those with single infection. However, focussing on a different level of education, and the frequency of infection within the educational level, we observed that the highest proportion was two to three times for any level of education. Patients with tertiary education have the lowest level of HIV and malaria co-infection, showing a strong association between the educational status and a decrease in HIV-malaria co-infection rate. Though, looking at the patient that never had any infection, patient with tertiary education presented with the highest proportion with no infection as the proportion with patient with different frequencies of infection (Figure 1).

As shown in Figure 2 above, patients that were formally employed had the lowest number of malaria infections. It was also observed that the peak of co-infection was two to three times for any of the employment status. Patients that were formally employed were made up of 32\%, 19\%, and 30\% without malaria infection. However, considering all the non-infections, formally employed patients contributed to the highest proportion of patients with no infection, $32 \%$ out of all the different infection rate, compared with the unemployed patients, which accounted for only $19 \%$ of the patient without infection.

Table 3. Association between socio-economic characteristics and number of times malaria diagnosed

\begin{tabular}{|c|c|c|c|}
\hline \multirow{2}{*}{$\begin{array}{l}\text { Variable } \\
\text { Education }\end{array}$} & \multicolumn{3}{|c|}{ Number of times malaria diagnosed } \\
\hline & None (n, (\%) & $\geq$ Once $(n,(\%)$ & P value \\
\hline No formal education & $127(23.2)$ & $422(76.8)$ & \\
\hline Completed primary & $107(28.1)$ & $275(71.9)$ & \\
\hline Completed secondary & $83(23.0)$ & $278(77.0)$ & \\
\hline \multirow[t]{2}{*}{ Completed tertiary } & $54(30.0)$ & $126(70.0)$ & 0.11 \\
\hline & 371 & 1,101 & \\
\hline \multicolumn{4}{|l|}{ Residence. $(\mathrm{N}=1442)$} \\
\hline Urban & $24(19.6)$ & $98(80.4)$ & \\
\hline Rural & $251(25.3)$ & $744(74.7)$ & \\
\hline \multirow[t]{2}{*}{ Peri-urban } & $96(29.5)$ & $229(70.5)$ & 0.08 \\
\hline & 371 & 1,071 & \\
\hline \multicolumn{4}{|l|}{ Distance from hospital } \\
\hline Less than 15 minutes & $14(35.9)$ & $25(64.1)$ & \\
\hline$>15$ to 30 minutes & $72(24.5)$ & $222(75.5)$ & \\
\hline$>30$ to 45 minutes & $119(23.3)$ & $391(76.7)$ & \\
\hline \multirow[t]{2}{*}{$\geq 45$} & $166(26.3)$ & $463(73.6)$ & 0.28 \\
\hline & 371 & 1,101 & \\
\hline \multicolumn{4}{|l|}{ Employment } \\
\hline Employed & $39(31.7)$ & $84(68.3)$ & \\
\hline Un-employed & $129(19.1)$ & $547(80.9)$ & \\
\hline \multirow[t]{2}{*}{ Self employed } & $203(30.2)$ & $470(69.8)$ & 0.000 \\
\hline & 371 & 1,101 & \\
\hline \multicolumn{4}{|c|}{ Average monthly income. $(\mathrm{N}=787)$. } \\
\hline Less than 30,000 & $182(31.1)$ & $403(68.9 \%)$ & \\
\hline$>30,000-80,000$ & $35(21.7)$ & $126(78.3 \%)$ & \\
\hline$>80,000-130,000$ & $19(47.5)$ & $21(52.5 \%)$ & \\
\hline \multirow[t]{2}{*}{$>130,000-180,000$} & $0(.0)$ & $1(100 \%)$ & 0.008 \\
\hline & 236 & 551 & \\
\hline
\end{tabular}

$1 \mathrm{USD}=363.67 \mathrm{NGN}$ in 2018. 
There is no significant relationship between the educational status of the patient, area of residence and distance from the hospital, with the likelihood of contracting malaria using a chi-square test with $p$-values of $0.11,0.08$ and 0.28 respectively. However, there is an association between employment status and average monthly income with the likelihood of malaria infection with $p$ - values of 0.000 and 0.008 respectively. Patient that were un-employed has the highest proportion of malaria diagnosis $547(80.9 \%)$, while the least proportion of malaria diagnosis was documented among the employed patient 84 (68.3\%) (Table 3).

Furthermore, a binary logistic regression model was used to predict HIV malaria co-infection among the study population, as shown in equation (i). The predictive accuracy of the model was $69.9 \%$.

$\log (\mathrm{P} / 1-\mathrm{P})=\mathrm{b}_{0}+\mathrm{b}_{1} * \mathrm{x}_{1}+\mathrm{b}_{2} * \mathrm{x}_{2}+\mathrm{b}_{\mathrm{n}} \mathrm{x}_{\mathrm{n}} \ldots \ldots \ldots \ldots$ (Eqn. $\left.\mathrm{i}\right)$

$\log (\mathrm{P} / 1-\mathrm{P})=21.02-20.41 *$ income $\ldots \ldots \ldots . . .($ Eqn. ii)

$(\mathrm{P} / 1-\mathrm{p})=\mathrm{e}$ : exponential ${ }^{21.02}-\mathrm{e}^{20.41} *$ e: exponential $*$ income.

Where $\mathrm{P}=$ probability of $\mathrm{HIV} /$ malaria co-infection and

$1-\mathrm{P}=$ probability of non-co-infection i.e, only HIV infected.

$\mathrm{P} / 1-\mathrm{p}$ is the proportion of patients that are co-infected over non co-infected patients. The proportion of co-infected over the only HIV infected patients is negatively related to the level of income of the patients. As the income level of the patient increases, there is a corresponding decrease in the likelihood of co-infection with malaria and HIV i.e the patients with lower income have higher risk of HIV/malaria co-infection.

$\mathrm{P} / 1$-p depicts the number of co-infected patients as a fraction of non-co-infected patients, i.e, HIV infected patients un-infected with malaria.

$\underline{\text { HIV positive + Malaria positive }}$

HIV positive.

\section{Discussion}

There is a high tendency of HIV/malaria co-infection interaction in geographical areas where both infections are widely distributed like NCZ Nigeria. The aim of this study was to determine the socio-economic variables associated with HIV/malaria co-infection. This study reported that age group 61 years and above and patients between 18 and 30 years old were found to be a risk factor for HIV/malaria co-infection when compared to other age bands (Table 1). This may be as a result of their predisposition to malaria infection, or involvement in activities that predispose them to mosquito bites and other related issues such as environmental conditions and occupations, in accordance with a related study conducted in Kogi state Nigeria (Akinbo et al., 2016) and in India (Bharti et al., 2012) respectively.

Increased risk of HIV/malaria co-infection was dominant amidst HIV positive patients who were single, while a higher rate of co-infection was reported among urban dwellers. This is contrary to what was observed by Dada et al., (Dada, 2015), where rural inhabitants were exposed to factors that support the proliferation of mosquitoes.

There is high level of awareness among patients with formal education and can take actions to prevent severe health problem. This will increase the likelihood of acquisition and the usage of malaria and HIV preventive and protective measures. As shown in Table 2, the least co-infected patients (5.5\%), have the highest income. Similarly, a significant association was reported between the likelihood of co-infection and education, residence, employment and income.

For any educational level, the highest frequency of infection observed was two to three times. Considering the educational level, the least level of co-infection was notable among patients with tertiary education (Skevington, 2010). Similarly, the highest proportion of patient with no infection was observed among patient with tertiary education (Lochner, 2011) (Figure 1a). Formally employed patient accounted for the highest proportion of those without infection $32 \%$, compared with only $19 \%$ of patient with no infection (Figure 1b).

Furthermore, a strong association was observed between the employment status and the number of times diagnosed for malaria. To further validate the findings of Izuka et al., from Ituku-Ozalla, Enugu (Izuka et al., 2017), and Kogi state Nigeria (Akinbo et al., 2016). This study noted that, there is an association between un-employed and self-employed with a notable reduced income associated with increased HIV/malaria co-infection (Table 3). Patient that were un-employed has the highest proportion of malaria diagnosis 547 (80.9\%), contrary to the least proportion documented among the employed patient 84 (68.3\%).

However, using a logistic regression model with a predictive accuracy of $69.9 \%$. It was observed that, the 
proportion of co-infection among HIV seropositive patients, is negatively associated with their income. There is a decrease in the likelihood of HIV malaria co-infection with an increase in income.

\section{Conclusion}

In this study, being single, living in urban areas, education, employment, income, above 61 years and between 18 and 30 years of age are socio-economic variables associated with HIV/malaria co-infection. A logistic regression model, estimated that, the higher the rate of co-infection among the study population, the decrease in the rate of income. These socio-economic factors associated with malaria infection among HIV seropositive patients across the six-study location in the NCZ, Nigeria could predict future HIV/malaria co-infection among HIV seropositive individuals, which might be an important indicator for disease prevention, and control. Similarly, this could also help health care providers working in HIV and malaria prevalent areas, like NCZ, Nigeria, to prioritize treatment based on the social-economic profile of the patients.

\section{Recommendation}

Future research study, preferably a prospective study is needed to establish socio-economic variables as predictors of HIV-malaria co-infection.

\section{Acknowledgements}

The authors are grateful to the Kwara, Nasarawa and Benue state ministry of health, and the management of the Hospital Management Board (HMB) for giving us the permission and granting us the required support. We also appreciate the staff at the selected semi-urban secondary hospital facilities where the study was conducted (specialist hospital Omu-Aran, specialist hospital Offa and the staff of Management Science for Health (MSH). General hospital Nasarawa-Eggon, general hospital Obi, and the staffs of pro-health international. Gboko general hospital and Katsina-Ala general hospital) for giving us all the necessary support and access to data for this research study.

\section{Author Contributions}

The study protocol was developed by O. S Alaofin and K. Naidoo. The collaboration and facilitation of the data collection at the six study locations where the study was conducted was harmonized by O. S. The data collection process, data analysis and presentation of the results were monitored by O. S and K. Naidoo. The manuscript was designed by O. S and K. Naidoo, and drafted and written by O.S. The statistical analysis was conducted by W. Sibanda. The development of the manuscript was monitored and reviewed, the final draft of the manuscript was edited and approved by O. S and K. Naidoo and W. Sibanda.

\section{Funding Statement}

This research project was funded by the University of KwaZulu-Natal College of Health Sciences. Findings and opinions from this study are those of the authors and do not reflect the stance of the funding organization and agency.

\section{Data Sharing}

The final manuscript was edited and approved by the authors, (O. S Alaofin, K. Naidoo and W. Sibanda).

\section{Competing Interests Statement}

The authors declare that they have no conflict of interest.

\section{References}

Adu-Gyasi, D., Fanello, C. I., Baiden, F., Porter, J. D. H., Korbel, D., Adjei, G., ... Owusu-Agyei, S. (2013). Prevalence of clinically captured and confirmed malaria among HIV seropositve clinic attendants in five hospitals in Ghana. Malaria Journal, 12(283), 1-7. Retrieved from https://www.ncbi.nlm.nih.gov/pubmed/24172232.

Akinbo, F. O., Anate, P. J., Akinbo, D. B., Omoregie, R., Okoosi, S., \& Abdulsalami, A. (2016). Prevalence of malaria among HIV patients on highly active antiretroviral therapy in Kogi State, North Central Nigeria. Annals of Nigerian Medicine, 10(1), 11-15. https://doi.org/10.4103/0331-3131.189802

Berg, A., Patel, S., Aukrust, P., David, C., Gonca, M., Berg, E. S., ... \& Langeland, N. (2014). Increased Severity and Mortality in Adults Co-infected with Malaria and HIV in Maputo, Mozambique: A Prospective Cross-Sectional Study. PLoS ONE, 9(2), e88257. https://doi.org/10.1371/journal.pone.0088257

Bharti, A. R., Saravanan, S., Madhavan, V., Smith, D. M., Sharma, J., Balakrishnan, P., ... Kumarasamy, N. (2012). Correlates of HIV and malaria co-infection in Southern India. Malaria Journal, 11(1), 306-309. 
https://doi.org/10.1186/1475-2875-11-306

Dada, E. O. (2015). Prevalence of Malaria and Co-infection with Human Immuno-Deficiency Virus (HIV) in Selected Areas of Ondo State, Nigeria. International Journal of Tropical Disease \& Health, 8(1), 34-39. https://doi.org/10.9734/IJTDH/2015/16987

Heiman, H., \& Artiga, S. (2015). Beyond Health Care: The Role of Social Determinants in Promoting Health and Health Equity. Retrieved September 25, 2017, from Kaiser Family Foundation. $\mathrm{http} / / \mathrm{kff}$. org/disparities-policy/issue-brief/beyond-health-care-the-role-of-socialdeterminants-in-promotinghealth-and-health-equity/.

Izuka, E. O., Ugwu, E. O., Obi, S. N., Ozumba, B. C., Nwagha, T. U., \& Obiora-Izuka, C. E. (2017). Prevalence and predictors of placental malaria in human immunodeficiency virus-positive women in Nigeria. Nigerian Journal of Clinical Practice, 20(1), 31-36. https://doi.org/10.4103/1119-3077.180077

Lochner, L. A. (2011). Non-production benefits of education: crime, health, and good citizenship, 16722, National Bureau ofEconomic Research (NBER). https://doi.org/10.3386/w16722

Mukandavire, M., Gumel, A. B., Garira, W., \& Tchuenche J. M. (2009). Mathematical analysis of a model for HIV-malaria co-infection. Mathematical Biosciences and Engineering, 6(2), 333-362. https://doi.org/10.3934/mbe.2009.6.333

Ogunmola, O. J., Oladosu, Y. O., \& Olamoyegun, M. A. (2014). Relationship between socioeconomic status and HIV infection in a rural tertiary health center. HIV/AIDS - Research and Palliative Care, 6(1), 61-67. https://doi.org/10.2147/HIV.S59061

Parcel, T. L., \& Mueller, C. W. (1983). Occupational Differenciation. Work and Occupations, 10(1), 49-80. https://doi.org/10.1177/0730888483010001004

Skevington, S. M. (2010). Qualities of life, educational level and human development: an international investigation of health. Soc Psychiat Epidemiol, 45(10), 999-1009. https://doi.org/10.1007/s00127-009-0138-x

Whitworth, J., Morgan, D., Quigley, M., Smith, A., Mayanja, B., \& Eotu, H. (2000). Effect of HIV-1 and increasing immunosuppression on malaria parasitaemia and clinical episodes in adults in rural Uganda: A cohort study. Lancet, 356(9235), 1051-1056. https://doi.org/10.1016/S0140-6736(00)02727-6

World Health Organization [WHO]. (2005). Malaria and HIV Interactions and their Implications for Public Health Policy. World Health Organization Geneva, Switzerland.

World Health Organization [WHO]. (2008). Roll Back Malaria Partnership: World Malaria Report. Organization. Geneva, Switzerland.

World Health Organization [WHO]. (2016). HIV/AIDS Fact sheet. World Health Organization

\section{Copyrights}

Copyright for this article is retained by the author(s), with first publication rights granted to the journal.

This is an open-access article distributed under the terms and conditions of the Creative Commons Attribution license (http://creativecommons.org/licenses/by/4.0/). 